\title{
Angioplasty as an Adjuvant Therapy for the Treatment of Acute Ischemic Stroke
}

\author{
Mohammed Alhazzaa, Amanda Murphy, Cheemun Lum, Marlise P. dos Santos, \\ Howard Lesiuk, Miguel Bussière
}

\begin{abstract}
Background: Different endovascular techniques can be employed to achieve vessel recanalization in acute stroke. We assessed whether an endovascular strategy that included angioplasty was safe and effectively recanalized acutely occluded intracranial vessels. Methods: We retrospectively reviewed 70 patients that received intra-arterial therapy for acute stroke. Patients were divided into two groups depending on whether they had received angioplasty as part of their endovascular treatment. Results: Angioplasty was used in the treatment of 35/70 patients (50\%). Median baseline NIHSS was 15 . The site of occlusion was at the M1 in 11 patients, M1/M2 in 3, ICA/M1 in 13 and vertebrobasilar in 8 patients. Intravenous thrombolysis was administered to 16/35 patients (46\%). Angioplasty was used alone in 4 patients, in combination with intra-arterial thrombolysis in 27 and with a mechanical retrieval device or stent in 13 patients. Recanalization (TICI 2-3) was achieved in 23/35 patients (66\%). Median time from symptom onset to recanalization was six hours. In patients where angioplasty was employed, symptomatic intracranial hemorrhage occurred in 2/35 (6\%), which was similar to patients that were not treated with angioplasty. A favorable functional outcome (mRS =2) was achieved in $20 \%(7 / 35)$ at 24 hour and $34 \%(12 / 35)$ at one month. All patients that had a favorable outcome had recanalized. Conclusion: In this small cohort, an endovascular treatment strategy that employed angioplasty was safe and effectively recanalized acutely occluded intracranial vessels. Angioplasty should be considered as a potential treatment option in interventional acute stroke trials.
\end{abstract}

RÉSUMÉ: La place de l'angioplastie dans le traitement de l'accident vasculaire cérébral ischémique aigu. Contexte : Différentes techniques endovasculaires peuvent être utilisées pour la reperméabilisation vasculaire dans l'accident vasculaire cérébral ischémique aigu (AVCA). Nous avons évalué si une stratégie endovasculaire incluant l'angioplastie était une méthode sûre et efficace de reperméabilisation lors de l'occlusion aiguë de vaisseaux intracrâniens. Méthode : Nous avons révisé rétrospectivement les dossiers de 70 patients qui ont reçu un traitement intra-artériel pour un AVC. Les patients ont été divisés en deux groupes, selon qu'ils avaient ou non subi une angioplastie au cours de leur traitement endovasculaire. Résultats : L'angioplastie a été utilisée chez 35 des 70 patients (50\%). Le score médian au NIHSS était de 15 avant traitement. Le site de l'occlusion était au niveau de M1 chez 11 patients, M1/M2 chez 3, ACI/M1 chez 13 et vertébrobasilaire chez 8 patients. Seize des 35 patients (46\%) ont reçu une thrombolyse intraveineuse. Une angioplastie seule a été effectuée chez 4 patients, combinée à une thrombolyse intra-artérielle chez 27 patients et à une thrombectomie mécanique ou une endoprothèse chez 13 patients. Chez 23 des 35 patients (66\%) la reperméabilisation a été un succès (TIMI 2-3). Le temps médian écoulé entre le début des symptômes et la reperméabilisation était de 6 heures. Chez les patients qui ont subi une angioplastie, 2 des 35 patients (6\%) ont subi une hémorragie intracrânienne symptomatique, soit une fréquence similaire à celle des patients qui n'ont pas subi d'angioplastie. Le résultat a été favorable au point de vue fonctionnel $(\mathrm{mRS}=2)$ chez $20 \%(7 / 35) 24$ heures après l'événement et chez $34 \%(12 / 35) 1$ mois après. L'artère était reperméabilisée chez tous les patients chez qui le résultat a été favorable. Conclusion : Dans cette petite cohorte, le traitement endovasculaire au moyen de l'angioplastie était sûr et reperméabilisait efficacement les vaisseaux intracrâniens en occlusion aiguë. L'angioplastie devrait être considérée comme option de traitement dans les essais cliniques interventionnistes portant sur l'AVCA.

Can. J. Neurol. Sci. 2011; 38: 593-599

Endovascular tools to assist in the recanalization of acutely occluded intracranial vessels and restoration of cerebral blood flow are rapidly evolving and expanding. Non-randomized trials suggest that these intra-arterial (IA) devices can increase the likelihood of recanalization of large artery occlusions compared to intravenous thrombolysis alone ${ }^{1-8}$. Numerous studies have demonstrated an association between recanalization and improved functional outcome ${ }^{9}$. This increased recanalization rate with endovascular therapy, however, comes with a potential increased risk of a serious adverse event such as intracranial hemorrhage. A direct comparison of the outcome of intravenous and intra-arterial (or combined intravenous and intra-arterial) therapy awaits the completion of large randomized controlled trials $^{10,11}$.
Recently developed tools, such as mechanical retrievers ${ }^{3}$, self-expanding stents ${ }^{4}$, thromboaspiration devices ${ }^{6}$ and stentretrieval devices ${ }^{7,8}$ may not be available at all stroke centers due to cost or lack of regulatory approval. Intra-arterial thrombolysis

\footnotetext{
From the Division of Neurology (MA, MB), Department of Medicine, Department of Diagnostic Imaging, Section of Interventional Neuroradiology (CL, MPdS, MB), Division of Neurosurgery (HL), Department of Surgery, The Ottawa Hospital, Ottawa; Department of Radiology (AM), Department of Medical Imaging, London Health Sciences Centre, London, Ontario, Canada.

Received November 19, 2010. Final Revisions Submitted February 11. 2011. Correspondence to: Miguel Bussiere, Neurology and Interventional Neuroradiology, The Ottawa Hospital, Civic campus, C2, Room 2174, 1053 Carling Avenue, Ottawa, Ontario, K1Y 4E9, Canada.
} 
and balloon angioplasty are tools that are widely available at all neurointerventional centers. Intra-arterial thrombolysis has been demonstrated to improve the outcome of patients with acute stroke due to middle cerebral artery (MCA) occlusion if administered within six hours of symptoms onset ${ }^{12,13}$. Few studies, however, have specifically examined the safety and efficacy of angioplasty as primary or adjunctive therapy in acute stroke ${ }^{14-25}$. Since angioplasty is not permitted in the treatment protocols of ongoing randomized interventional acute stroke trials ${ }^{10,11}$, further evidence of the utility of this treatment modality in acute stroke will depend on analysis of nonrandomized data sources.

We have previously reported our initial experience using clot angioplasty for acute anterior circulation stroke ${ }^{20}$. The purpose of this study was to determine whether an endovascular strategy that utilizes angioplasty is a safe and effective approach for the treatment of acute stroke due to large vessel occlusion.
A 2000 unit bolus of heparin was administered immediately after femoral sheath insertion. Angiography was performed via a guiding catheter positioned in the proximal internal carotid artery (ICA) or vertebral artery to demonstrate the proximal extent of occlusive thrombus and assess progress. Microcatheter contrast injections distal to the occlusive thrombus were minimized given their association with an increased risk of intracranial hemorrhage ${ }^{26}$.

The precise endovascular treatment protocol utilized (tools and sequence of use) was at the discretion of the treating neurointerventionalist, but included one or more of the following modalities: intra-arterial lytics (tissue plasminogen activator (tPA) or abciximab), microwire/microcatheter clot maceration, mechanical retriever (MERCI, Concentric Medical, Mountain View, CA), balloon angioplasty or stenting. Stent retrievers and thromboaspiration devices were not utilized in the treatment of patients in this cohort. The initial modality utilized was either

\section{Patients And Methods}

This study was approved by the institutional research ethics board. We retrospectively reviewed 70 consecutive patients presenting with acute ischemic stroke due to large vessel occlusion and treated with endovascular therapy from June 2002 to September 2009 at a single centre. Baseline clinical, imaging and angiographic information was retrospectively collected (Table 1). Disability was assessed using the National Institutes of Health Stroke Scale (NIHSS) and modified Rankin scale (mRS). A mRS score of $0-2$ at one month was considered a favorable outcome. Three month follow-up data was incomplete and therefore not provided.

Patients were initially considered for intravenous thrombolysis as per the institutional protocol. They were then considered for endovascular therapy if they: (a) had a disabling neurological deficit (b) had a non-contrast head computed tomogram (CT) without evidence of extensive early ischemic changes (c) had a CT angiography demonstrating a large proximal vessel occlusion (ICA/M1/M2/vertebrobasilar) (d) could be transferred to the angiography suite for initiation of endovascular therapy within 4.5 hours of symptom onset or longer for patients with posterior circulation ischemia (considered on an individual basis). There was no age limitation.

\section{Endovascular procedure}

Patients underwent selective angiography and endovascular treatment under conscious sedation and using local analgesia. General anesthesia was only utilized if there was concern about a patient's respiratory or cardiovascular status $(n=14)$.

Table 1: Baseline characteristics

\begin{tabular}{|c|c|c|c|}
\hline Variables & $\begin{array}{l}\text { Angioplasty Group } \\
\qquad \mathrm{N}=35\end{array}$ & $\begin{array}{l}\text { Non-Angioplasty Group } \\
\qquad \mathrm{N}=35\end{array}$ & $\begin{array}{c}\text { Overall } \\
\text { Group } \\
\mathrm{N}=70\end{array}$ \\
\hline \multicolumn{4}{|l|}{ Demographics } \\
\hline Age, mean (range) & $65(32-90)$ & $67(33-90)$ & $66(32-90)$ \\
\hline Male n $(\%)$ & $23(66)$ & $21(60)$ & $44(63)$ \\
\hline \multicolumn{4}{|l|}{ Vascular risk factors } \\
\hline Hypertension $\mathrm{n}(\%)$ & $21(60)$ & $17(49)$ & $38(54)$ \\
\hline Diabetes n $(\%)$ & $6(17)$ & $3(9)$ & $9(13)$ \\
\hline Hyperlipidemia n (\%) & $15(43)$ & $8(23)$ & $23(33)$ \\
\hline CAD n $(\%)$ & $16(46)$ & $5(14)$ & $21(30)$ \\
\hline Prior stroke/TIA n $(\%)$ & $7(20)$ & $5(14)$ & $12(17)$ \\
\hline PVD n $(\%)$ & $3(9)$ & 0 & $3(4)$ \\
\hline Smoking $\mathrm{n}(\%)$ & $12(34)$ & $9(26)$ & $21(30)$ \\
\hline Atrial fibrillation $\mathrm{n}(\%)$ & $10(29)$ & $7(20)$ & $17(24)$ \\
\hline $\begin{array}{l}\text { Severe ipsilateral } \\
\text { carotid stenosis n (\%) }\end{array}$ & $4(11)$ & $1(3)$ & $5(7)$ \\
\hline Baseline NIHSS, median (range) & $15(3-24)$ & $17(7-29)$ & $16(3-29)$ \\
\hline$<10, \mathrm{n}(\%)$ & $14(40)$ & $18(41)$ & $32(46)$ \\
\hline $10-19, \mathrm{n}(\%)$ & $17(49)$ & $12(34)$ & $29(41)$ \\
\hline$\geq 20, \mathrm{n}(\%)$ & $4(11)$ & $5(14)$ & $9(13)$ \\
\hline \multicolumn{4}{|l|}{ Baseline CT head } \\
\hline ASPECTS, median (range)* & $9(7-10)$ & $9(7-10)$ & $9(7-10)$ \\
\hline$<4, \mathrm{n}(\%)$ & 0 & 0 & 0 \\
\hline $4-7, \mathrm{n}(\%)^{* *}$ & $5 / 27(19)$ & $8 / 29(28)$ & $13 / 56(23)$ \\
\hline $8-10, \mathrm{n}(\%)$ & $22 / 27(81)$ & $21 / 29(72)$ & $43 / 56(77)$ \\
\hline pcASPECTS,median (range) & $8(7-10)$ & $9.5(8-10)$ & $9(7-10)$ \\
\hline$<4, \mathrm{n}(\%)$ & 0 & 0 & 0 \\
\hline $4-7, \mathrm{n}(\%)^{* *}$ & $2 / 6(33)$ & 0 & $2 / 6(33)$ \\
\hline $8-10, \mathrm{n}(\%)$ & $4 / 6(67)$ & $4 / 4(100)$ & $8 / 10(80)$ \\
\hline \multicolumn{4}{|l|}{ Presumed stroke etiology } \\
\hline Cardioembolic, n (\%) & $16(46)$ & $9(26)$ & $25(36)$ \\
\hline Large vessel, n (\%) & $4(11)$ & $1(3)$ & $5(7)$ \\
\hline Dissection, $\mathrm{n}(\%)$ & $1(3)$ & $3(9)$ & $4(6)$ \\
\hline Uncertain, n (\%) & $14(40)$ & $22(63)$ & $36(51)$ \\
\hline
\end{tabular}

CAD, coronary artery disease; PVD, peripheral vascular disease; NIHSS, National Institutes of Health Stroke Scale; ASPECTS, Alberta Stroke Program Early CT Score; pcASPECTS, posterior circulation Alberta Stroke Program Early CT Score.

* Four baseline scans were not available for review. ** No patients had a baseline ASPECTS or pcASPECTS $<6$. 
intra-arterial tPA administration or mechanical thrombectomy/ retrieval in patients with appropriate vascular anatomy. Intraarterial lytics were administered via a microcatheter positioned at the proximal edge or within the occlusive thrombus. The median intra-arterial tPA and abciximab doses given were $11 \mathrm{mg}$ and $7 \mathrm{mg}$, respectively. Clot maceration was often performed by carefully and repeatedly traversing the thrombus with microwire and microcatheter.

Angioplasty was generally considered only after inadequate or failed recanalization with lytic agent, mechanical thrombectomy or both. In four patients, angioplasty was the only endovascular modality utilized. Angioplasty was performed using $4 \mathrm{~mm}$ x 10 or $20 \mathrm{~mm}$ HyperGlide or $4 \mathrm{~mm} \times 7 \mathrm{~mm}$ HyperForm balloons (ev3, Irvine, CA), sized according to clot location and estimated vessel diameter (M1 or M2 segment or basilar artery). Multiple slow and gentle inflations of 10-20 second duration were performed under roadmap guidance, repositioning the balloon along the occluded segment between inflations.

The procedure was terminated if recanalization was achieved, the elapsed time from onset of symptoms was greater than six hours (or longer for patients with posterior circulation ischemia, 12 hours being the longest in one patient) or due to perceived treatment futility. In patients with severe proximal ICA or vertebrobasilar stenosis, stents were placed only if distal flow was perceived to be inadequate and there was felt to be an elevated risk of re-thrombosis. Dual antiplatelet therapy was administered during procedures where stents were deployed.

\section{Imaging}

Baseline non-contrast CT head (NCCT) images (or magnetic resonance imaging (MRI) diffusion weighted images when available) were reviewed (MB, MA) for determination of the extent of baseline early ischemic change quantified using the ASPECTS (anterior circulation) ${ }^{27}$. The computed tomogram angiography (CTA) sources images of patients with vertebrobasilar ischemia were assessed for determination of pcASPECTS score ${ }^{28}$. The site of arterial occlusion (ICA, M1, M2, M1/M2, ICA/M1 and vertebrobasilar) was determined by reviewing CTA angiograms of the head and neck (MB, MA). Pre- and post-endovascular treatment angiograms were reviewed (MB, MA) and recanalization was graded according to the Thrombolysis in Cerebral Infarction (TICI) grading system: Grade 0: no perfusion, Grade 1: minimal perfusion, Grade 2: partial perfusion, Grade 3: complete perfusion ${ }^{29}$. Recanalization was defined as a TICI 2-3 and no recanalization was considered as a TICI 0-1.

Follow-up NCCT obtained 24 hours after treatment were reviewed for evidence of hemorrhagic transformation and graded according to the ECASS classification: HI-1 (small petechiae); HI-2 (confluent petechiae); $\mathrm{PH}-1$ (hematoma in $<30 \%$ of the infarcted area, with a mild space-occupying effect); and $\mathrm{PH}-2$ (hematoma in $>30 \%$ of the infarcted area, with a significant space-occupying effect) ${ }^{30}$. Any subarachnoid or intraventricular hemorrhage was graded as PH-2. Symptomatic intracranial hemorrhage $(\mathrm{sICH})$ was defined as a 4 point or greater deterioration of NIHSS status in the first 24 hours after intraarterial therapy attributable to a hemorrhage seen on the followup CT scan.

\section{Statistical analysis}

Statistical analysis was performed using descriptive statistics and Student $\mathrm{t}$ distribution for paired samples. A two-tailed $\mathrm{p}<0.05$ was considered significant. Direct statistical comparisons between treatment groups (angioplasty and no angioplasty) was not performed since groups were not randomly selected and treatment group allocation was dependent on findings at the time of angiography and treating physician preference.

\section{RESUlts \\ Baseline characteristics}

Baseline clinical information for patients that received endovascular acute stroke therapy is presented in Tables 1 and 2 $(n=70)$. In patients that received angioplasty as a component of their endovascular intervention $(n=35)$, the mean age was 65 with a median baseline NIHSS $=15$. Twenty seven $(27 / 35,77 \%)$ patients had an anterior circulation stroke and 8/35 (23\%) a posterior circulation event. The site of arterial occlusion was at the M1 segment in 11 patients, M1/M2 in 3, ICA/M1 in 13 (including tandem and T-occlusions) and vertebrobasilar in 8 patients (Table 2). Median baseline ASPECTS was 9 for patients with anterior circulation ischemia and median pcASPECTS was 8 for patients with vertebrobasilar ischemia. Intravenous tPA was administered to $46 \%(16 / 35)$ of patients with median time from symptom onset to IV tPA administration of two hours. Nineteen patients were outside the time window for IV tPA administration or had contraindications to systemic pharmacological thrombolysis.

\section{Endovascular treatment}

Median time from symptom onset to endovascular therapy was four hours (Table 2). Angioplasty was the only endovascular tool used in four patients $(4 / 35,11 \%)$. Balloons were used in combination with other interventional tools in $31 / 35$ patients $(89 \%)$. Intra-arterial lytic agents (tPA, abciximab or both) were co-administered before or after angioplasty in 27 patients. In six patients mechanical thrombectomy (MERCI retriever) was attempted prior to angioplasty. Angioplasty was the final or only modality utilized in 19/35 (54\%). Eight patients had three or more endovascular modalities used in the course of treatment and among these, angioplasty was the final modality used in only one patient. After intracranial vessel recanalization was complete, a stent was placed to improve distal flow in seven patients with a severe residual stenosis of the cervical internal carotid (4/7) or vertebrobasilar (3/7) arteries.

\section{Recanalization}

The overall recanalization rate of acute arterial occlusions after endovascular therapy was 59\% (41/70). In patients where angioplasty was used as one step of the endovascular protocol, recanalization was achieved in 23/35 (66\%). Thrombolysis in Cerebral Infarction (TICI) 2-3 flow was achieved in 20 of these 23 patients after the angioplasty step alone. Median time from symptom onset to recanalization was six hours. 
Table 2: Procedural data

\begin{tabular}{|c|c|c|c|}
\hline Variables & $\begin{array}{l}\text { Angioplasty Group } \\
\qquad \mathbf{N}=\mathbf{3 5}\end{array}$ & $\begin{array}{c}\text { Non-Angioplasty } \\
\text { Group } \\
\mathbf{N}=\mathbf{3 5} \\
\end{array}$ & ${ }_{\mathbf{N}=\mathbf{7 0}}^{\text {Overall Group }}$ \\
\hline \multicolumn{4}{|l|}{ Thrombus location, n (\%) } \\
\hline M1 & $11(31)$ & $11(31)$ & $22(31)$ \\
\hline M1/M2 & $3(9)$ & $9(26)$ & $12(17)$ \\
\hline $\mathrm{ICA} / \mathrm{M} 1 *$ & $13(37)$ & $11(31)$ & $24(34)$ \\
\hline Vertebrobasilar & $8(23)$ & $4(11)$ & $12(17)$ \\
\hline \multicolumn{4}{|l|}{ Time, hours, mean (range) } \\
\hline Onset to ER & $1.6(0.1-7)$ & $1.8(0.5-6)$ & $2(0.1-7)$ \\
\hline Onset to IV tPA & $2.2(1-4)$ & $2.4(1-4)$ & $2(1-4)$ \\
\hline Onset to groin puncture & $4(2-9)$ & $4(1.5-10)$ & $4(1.5-10)$ \\
\hline Onset to end of IA & $6(2.5-12)$ & $6(4-13)$ & $6(2.5-13)$ \\
\hline IV tPA & $16(46)$ & $23(66)$ & $39(56)$ \\
\hline \multicolumn{4}{|l|}{ IA treatment modality, $\mathrm{n}(\%)^{* *}$} \\
\hline IA lytics (tPA,abciximab) & $27(77)$ & $33(94)$ & $60(86)$ \\
\hline Mechanical retriever & $6(17)$ & $14(40)$ & $20(29)$ \\
\hline Stent: Extracranial ICA & $4(11)$ & $1(3)$ & $5(7)$ \\
\hline Basilar a. ${ }^{* * *}$ & $3(9)$ & 0 & $3(4)$ \\
\hline \multicolumn{4}{|l|}{ Number of IA modalities } \\
\hline One & $4(11)$ & $25(71)$ & $29(41)$ \\
\hline Two & $23(66)$ & $10(29)$ & $33(47)$ \\
\hline Three & $7(20)$ & 0 & $7(10)$ \\
\hline more & $1(3)$ & 0 & $1(1)$ \\
\hline
\end{tabular}

IV, intravenous; IA, intra-arterial; tPA, Tissue plasminogen activator; ICA, internal carotid artery; M1 or M2, proximal middle cerebral artery segments; ER, emergency room.

* Including tandem and T-occlusions. ** Four patients had angioplasty alone. *** One patient had a stent placed in a proximal vertebral artery. were discharged home or to stroke rehabilitation (Table 3). The overall mortality rate in this group was $9 / 35$ $(26 \%)$ at 30 days.

\section{DISCUSSION}

The ideal endovascular tool to assist in recanalization of acutely occluded vessels should be easy to use, rapidly positioned into place and safely and consistently achieve a high rate of vessel recanalization. Unfortunately, no single intra-arterial device developed to date meets all these criteria. A multimodal treatment strategy is necessary, tailored to each individual patient and based on operator familiarity and tool availability. Newer tools such as the latest iteration of mechanical and stent retrievers or thromboaspiration devices are not universally available at all tertiary stroke centers due to cost or lack of regulatory approval $^{2,6-8}$. In contrast, angioplasty is widely available in most neurointerventional centers and balloons can be rapidly prepared and positioned into place. In our cohort, angioplasty used alone or in combination with other modalities was safe with a low sICH rate of $6 \%$. Partial or complete vessel recanalization was achieved in $66 \%$ of patients and in these patients $87 \%(20 / 23$

\section{Intracranial hemorrhage}

Symptomatic intracerebral hemorrhage occurred in 2/35 (6\%) patients in the angioplasty group (Table 3). In one patient, angioplasty was combined with intra-arterial tPA and in one patient mechanical retrieval with the MERCI device was attempted prior to angioplasty. The incidence of sICH was similar in patients that had not received angioplasty at any point during the endovascular treatment protocol $(2 / 35,6 \%)$ (Table 3$)$. No arterial dissections or ruptures were observed in patients treated with angioplasty.

\section{Clinical outcome}

The median NIHSS at baseline was 15, 11 at 24 hours and 7 at one month. In the angioplasty group, a favorable clinical outcome (mRS 0-2) was achieved in 7/35 (20\%) patients at 24 hours and 12/35 (34\%) patients at one month of follow-up (Table $3)$. In the angioplasty group, recanalization was strongly associated with a favorable outcome $(\mathrm{p}<0.002)$. In patients with vessel recanalization, 52\% (12/23 patients) had a favorable outcome at one month. In contrast, $0 / 12$ patients with persistent large vessel occlusion at the end of treatment had a favorable outcome at one month. A similar correlation of recanalization with good outcome was seen in the non-angioplasty group, with $11 / 18(61 \%)$ patients that recanalized achieving a good outcome compared to $2 / 17(12 \%)$ patients that did not recanalize $(p=0.03)$. Sixteen patients $(16 / 35,46 \%)$ in the angioplasty group patients) recanalized immediately after angioplasty.

The rates of recanalization and sICH observed in our cohort of patients treated with angioplasty are similar to those reported previously. Ueda et al reported recanalization in 11/13 patients with one asymptomatic petechial hemorrhage in patients treated with angioplasty and intra-arterial thrombolytic ${ }^{14,15}$. In another small series, recanalization occurred in 5/9 patients with one hemorrhage ${ }^{16}$. Percutaneous angioplasty in combination with intra-arterial thrombolysis resulted in partial or complete recanalization in $91 \%(31 / 34)$ of patients, at the expense of development of three small and one massive intracranial hemorrhages ${ }^{18}$. Recanalization rates were $75 \%, 90.9 \%$ and $91.6 \%$ in three additional small case series in patients treated with angioplasty, in conjunction with other endovascular modalities, with no symptomatic intracerebral hemorrhages reported $^{20-22}$.

Reported rates of recanalization in acute stroke trials evaluating various neuro-interventional tools include: $66 \%$ with intraarterial urokinase ${ }^{12}, 48 \%$ with the MERCI mechanical retriever alone ${ }^{3}, 68 \%$ with the mechanical retriever in combination with thrombolytics $^{3}, 80 \%$ with thromboaspiration ${ }^{6}$ and as high as $90 \%$ with stent retrievers ${ }^{8}$. Some potential explanations for the variation in reported rates of recanalization aside from device differences alone include: differences in clot location, extent and composition and time windows for endovascular therapy. None of the patients with anterior circulation stroke in our cohort were treated beyond six hours 
Table 3: Procedural and clinical outcome

\begin{tabular}{|c|c|c|c|}
\hline Variables & $\begin{array}{l}\text { Angioplasty Group } \\
\qquad \mathbf{N}=\mathbf{3 5}\end{array}$ & $\begin{array}{l}\text { Non-Angioplasty Group } \\
\qquad \mathbf{N}=35\end{array}$ & $\begin{array}{c}\text { Overall } \\
\text { Group } \\
\mathbf{N}=70\end{array}$ \\
\hline Recanalization (TICI 2-3) & $23(66)$ & $18(51)$ & $41(59)$ \\
\hline \multicolumn{4}{|l|}{ Peri-procedural complications } \\
\hline Groin hematoma & 0 & $3(9)$ & $3 / 70(4)$ \\
\hline Arterial dissection & 0 & 0 & 0 \\
\hline Arterial perforation/rupture & 0 & $1(3)$ & $1(1)$ \\
\hline Any hemorrhage & $11(31)$ & $16(46)$ & $27(39)$ \\
\hline sICH & $2(6)$ & $2(6)$ & $4(6)$ \\
\hline NIHSS $24 \mathrm{~h}$, median (range) & $12(1-20)$ & $5(0-25)$ & $10(0-25)$ \\
\hline$<10, \mathrm{n}(\%)$ & $14(40)$ & $20(57)$ & $34(49)$ \\
\hline $10-19, \mathrm{n}(\%)$ & $17(49)$ & $10(29)$ & $27(39)$ \\
\hline$\geq 20, \mathrm{n}(\%)$ & $4(11)$ & $5(14)$ & $9(13)$ \\
\hline NIHSS, 30 days, median (range) & $6(0-18)$ & $4(0-25)$ & $4(0-25)$ \\
\hline$<10, \mathrm{n}(\%)$ & $13 / 24(54)$ & $14 / 21(67)$ & $27 / 45(60)$ \\
\hline $10-19, \mathrm{n}(\%)$ & $11 / 24(46)$ & $6 / 21(29)$ & $17 / 45(38)$ \\
\hline$\geq 20, \mathrm{n}(\%)$ & $0 / 24$ & $1 / 21(5)$ & $1 / 45(2)$ \\
\hline \multicolumn{4}{|l|}{ mRS $0-2, n(\%)$} \\
\hline 24 hours & $7(20)$ & $10(29)$ & $17(24)$ \\
\hline 30 days & $12(34)$ & $13(37)$ & $25(36)$ \\
\hline Mortality, 30 days, $\mathrm{n}(\%)$ & $9(26)$ & $8(23)$ & $17(24)$ \\
\hline LOS days, mean (range) & $13(2-55)$ & $16(2-65)$ & $14(2-65)$ \\
\hline \multicolumn{4}{|l|}{ Disposition, $\mathrm{n}(\%)^{*}$} \\
\hline Home & $10(29)$ & $13(37)$ & $23(33)$ \\
\hline Rehabilitation Facility & $6(18)$ & $11(31)$ & $17(24)$ \\
\hline Nursing Home & $9(26)$ & $3(9)$ & $12(17)$ \\
\hline
\end{tabular}

LOS; Length of Stay, sICH; symptomatic intracerebral hemorrhage, TICI;Thrombolysis in

Cerebral Infarction , NIHSS; National Institutes of Health Stroke Scale, mRS; modified Rankin scale. * One patient was transferred to another country and final disposition is unknown.

from time of symptom onset. The time window from symptom onset to recanalization ranged between 1-16 hours for anterior circulation strokes in other series.

A recent meta-analysis of 33 studies reporting recanalization and functional outcome after acute stroke, regardless of treatment received, demonstrated that vessel recanalization correlated strongly with outcome ${ }^{9}$. A favorable outcome (mRS 02) was achieved in $325 / 559(58.1 \%)$ patients that recanalized versus $109 / 439(24.8 \%)$ patients that did not recanalize (OR $4.43,95 \%$ CI 3.32-5.91). We found an equally strong correlation of outcome with recanalization with $52 \%$ of recanalizers in the angioplasty group having a favorable outcome vs. $0 \%$ of nonrecanalizers $(\mathrm{p}=0.002)$. Similar observations have been made in other interventional acute stroke case series and trials ${ }^{30,31}$. In the PROACT II study, the rate of recanalization was $66 \%$ in the endovascular group with $40 \%$ achieving a good clinical outcome compared to only $18 \%$ recanalization in the placebo group with $25 \%$ achieving good outcome ${ }^{12}$. The ratio of good clinical outcome in recanalizers vs. non-recanalizers in non-randomized trials was: IMS I-II $45.6 \% / 6.9 \%^{1,2}$ MERCI I 46\% / $10.4 \%{ }^{3}$, Multi MERCI 49.1\% / 9.6\% $\%^{3}$, Penumbra 29\% / 9\% . Time to recanalization is also likely be an important factor with the probability of a good clinical outcome decreasing as time to angiographic recanalization increase ${ }^{32}$. In addition, although not routinely utilized, 14 patients in our cohort required intubation and mechanical ventilation due to respiratory or cardiovascular compromise. General anesthesia may be associated with worse outcome after interventional stroke therapy ${ }^{33,34}$.

Futile recanalization is defined as failure of clinical improvement despite successful recanalization and reflects patients in whom there was no or little salvageable ischemic brain tissue by the time revascularization was achieved ${ }^{35}$. Eleven out of twenty-three $(47.8 \%)$ patients that recanalized in our cohort had a poor outcome. In ProACT II, $26 \%$ of patients that recanalized had a poor clinical outcome. The recanalization to favorable outcome mismatch was $45 \%$ in IMS, $34 \%$ in MERCI and $36 \%$ in Multi-MERCI ${ }^{36}$. Several factors have been found to predict clinical outcome after intraarterial therapy for acute stroke including age, baseline stroke severity, extent of hypodensity on baseline non-contrast CT head, hyperglycemia and location of vessel occlusion ${ }^{35-37}$. Imbalances in these factors likely explain the differences in outcome found between studies. Careful consideration of these factors may help identify patients with the greatest potential to benefit from endovascular therapy and minimize the rate of futile recanalization. Perfusion imaging may further help identify patients with salvageable brain tissue $^{38,39}$. 


\section{Limitations}

This study has several limitations inherent to its retrospective design. Long term follow up was incomplete and therefore three month or longer follow-up was unavailable. Angioplasty was part of a multimodal intraarterial treatment approach in the majority of patients and, therefore, establishment of reperfusion or adverse effects cannot be attributed to angioplasty alone. Several different operators with variable experience, training background and treatment approaches performed the endovascular procedures in this cohort of patients. It was not possible to evaluate how this might have affected outcome. Differences in patient outcome or response to a specific treatment modality may also relate to clot composition or extent which was not evaluated in this study.

\section{Conclusions}

In this small cohort, an endovascular treatment strategy that employed angioplasty was safe and effectively recanalized acutely occluded intracranial vessels. Angioplasty should be considered as a potential treatment option in interventional acute stroke trials.

\section{REFERENCES}

1. Broderick J, Tomsick T, Pancioli A, et al (for IMS study investigators). Combined intravenous and intra-arterial recanalization for acute ischemic stroke: the interventional management of stroke study. Stroke. 2004;35;904-11.

2. Tomsick T, Broderick J, Carrozellaa J, et al. (for IMS II study investigators). The Interventional management of stroke (IMS) II study. Stroke. 2007;38:2127-35.

3. Smith WS, Sung G, Saver J, et al. Mechanical thrombectomy for acute ischemic stroke: final results of the Multi MERCI trial. Stroke. 2008;39:1205-12.

4. Zaidat OO, Wolfe T, Hussain SI, et al. Interventional acute ischemic stroke therapy with intracranial self-expanding stent. Stroke. 2008;39:2392-5.

5. Brekenfeld C, Schroth G, Mattle HP, et al. Stent placement in acute cerebral artery occlusion: use of a self-expandable intracranial stent for acute stroke treatment. Stroke. 2009;40:847-52.

6. The Penumbra Pivotal Stroke Trial Investigators. Safety and effectiveness of a new generation of mechanical devices for clot removal in intracranial large vessel. Stroke. 2009;40:2761-8.

7. Castano C, Dorado L, Guerrero C, et al. Mechanical thrombectomy with the solitaire $\mathrm{AB}$ device in large artery occlusions of the anterior circulation. Stroke. 2010;41:1836-40.

8. Roth C, Papanagiotou P, Behnke S, et al. Stent-assisted mechanical recanalization for treatment of acute intracerebral artery occlusions. Stroke. 2010;41:2559-67.

9. Rha J-H, Saver JL. The impact of recanalization on ischemic stroke outcome, a meta-analysis. Stroke. 2007;38:967-73.

10. Khatri P, Hill M, Palesch Y, et al. (for the IMS III investigators). Methodology of the interventional management of stroke III Trial. Int J Stroke. 2008;3:130-7.

11. ClinicalTrials.gov [homepage on the Internet]. MR and recanalization of stroke clots using embolectomy. Betheseda, Maryland: U.S. National Institute of Health [updated 2010 Jun 23; cited $2011 \mathrm{Feb} 11]$. Available from: http://clinicaltrials.gov/ ct2/show/NCT00389467.

12. Furlan A, Higashida R, Wechsler $\mathrm{L}$, et al. Intra-arterial prourokinase for acute ischemic stroke. The PROACT II study: a randomized controlled trial. Prolyse in acute cerebral thromboembolism. JAMA. 1999;282:2003-11.

13. Ogawa A, Mori E, Minematsu K, et al. Randomized trial of intraarterial infusion of urokinase within 6 hours of middle cerebral artery stroke: the middle cerebral artery embolism local fibrinolytic intervention trial (MELT). Stroke. 2007;38:2633-9.
14. Ueda T, Hatakeyama T, Kohno K, et al. Endovascular treatment of acute thrombotic occlusion of the middle cerebral artery: local intra-arterial thrombolysis combined with percutaneous transluminal angioplasty. Neuroradiology. 1997;39:99-104.

15. Ueda T, Sakaki S, Nochide I, et al. Angioplasty after intraarterial thrombolysis for acute occlusion of intracranial arteries. Stroke. 1998;29:2568-74.

16. Ringer AJ, Qureshi AI, Fessler RD, et al. Angioplasty of intracranial occlusion resistant to thrombolysis in acute ischemic stroke. Neurosurgery. 2001;48:1282-8; discussion 1288-90.

17. Nakano S, Yokogami K, Ohta H, Yano T, Ohnishi T. Direct percutaneous transluminal angioplasty for acute middle cerebral artery occlusion. AJNR Am J Neuroradiol. 1998;19:767-72.

18. Nakano $S$, Iseda $T$, Yoneyama $T$, et al. Direct percutaneous transluminal angioplasty for acute middle cerebral artery trunk occlusion: an alternative option to intra-arterial thrombolysis. Stroke. 2002; 33:2872-6.

19. Lum C, Stys PK, Hogan MJ, et al. Acute anterior circulation stroke: recanalization using clot angioplasty. Can J Neurol Sci. 2006;33: 217-22.

20. Noguiera RG, Schwamm LH, Buonanno FS, et al. Low-pressure balloon angioplasty with adjuvant pharmacological therapy in patients with acute ischemic stroke caused by intracranial arterial occlusions. Neuroradiology. 2008; 50:331-40.

21. Quereshi AI, Siddiqui AM, Suri MFK, et al. Aggressive mechanical clot disruption and low-dose intraarterial third-generation thrombolytic agent for ischemic stroke: a prospective study. Neuorosurgery. 2002;51:1319-26.

22. Abou-Chebl A, Bajzer CT, Krieger DW, et al. Multimodal therapy for the treatment of severe ischemic stroke combining GPIIb/IIIa antagonists and angioplasty after failure of thrombolysis. Stroke. 2005;36:2286-8.

23. Yoneyama $\mathrm{T}$, Nakano $\mathrm{S}$, Kawano $\mathrm{H}$, et al. Combined direct percutaneous transluminal angioplasty and low dose native tissue plasminogen activator therapy for acute embolic middle cerebral artery trunk occlusion. AJNR Am J Neuroradiol. 2002; 23:277-81

24. Mori T, Kazita K, Mima T, Mori K. Balloon angioplasty for embolic total occlusion of the middle cerebral artery and ipsilateral carotid stenting in an acute stroke stage. AJNR Am J Neuroradiol. 1999;20:1462-4.

25. Barber PA, Demchuk AM, Zhang J, Buchan AM. Validity and reliability of a quantitative computed tomography score in predicting outcome of hyperacute stroke before thrombolytic therapy. ASPECTS study group. Lancet. 2000;355(9216): 1670-4.

26. Khatri P, Broderick JP, Khoury JC, Carrozzella JA, Tomsick TA. Microcatheter contrast injections during intra-arterial thrombolysis may increase intracranial hemorrhage risk. Stroke. 2008;39:3283-7.

27. Puetz V, Sylaja PN, Coutts SB, et al. Extent of hypoattenuation on CT angiography source images predicts functional outcome in patients with basilar artery occlusion. Stroke. 2008;39:2485-90.

28. Higishida RT, Furlan AJ, Roberts $\mathrm{H}$, et al. Trial design and reporting standards for intra-arterial cerebral thrombolysis for acute ischemic stroke. Stroke. 2003;34:109-37.

29. Hacke W, Kaste M, Fieschi C, et al. Intravenous thrombolysis with recombinant tissue plasminogen activator for acute hemispheric stroke: the European cooperative acute stroke study (ECASS). JAMA. 1995;274:1017-25.

30. Nogueira RG, Smith WS. Safety and efficacy of endovascular thrombectomy in patients with abnormal hemostasis: pooled analysis of the MERCI and multi MERCI trials. Stroke. 2009; 40:516-22.

31. Tomsick T, Broderick J, Carrozella J, et al. Revascularization results in the interventional management of stroke II trial. AJNR Am J Neuroradiol. 2008;29:582-7.

32. Khatri P, Abruzzo T, Yeatts SD, et al. Good clinical outcome after ischemic stroke with successful revascularization is timedependent. Neurology. 2009;73:1066-72. 
33. Nichols C, Carrozzella J, Yeatts S, et al. Is periprocedural sedation during acute stroke therapy associated with poorer functional outcomes? J NeuroIntervent Surg. 2010;2:67-70.

34. Abou-Chebl A, Lin R, Hussain MS, et al. Conscious sedation versus general anesthesia during endovascular therapy for acute anterior circulation stroke. Preliminary results from a retrospective, multicenter study. Stroke. 2010; 41:1175-9.

35. Hussein HM, Georgiadis AL, Vazquez G, et al. Occurrence and predictors of futile recanalization following endovascular treatment among patients with acute ischemic stroke: a multicenter study. AJNR Am J Neuroradiol. 2010;31(3):454-8.
36. Molina CA. Futile recanalization in mechanical embolectomy trials. Stroke. 2010;41:842-3.

37. Hallevi $\mathrm{H}$, Barreto $\mathrm{AD}$, Liebeskind $\mathrm{DS}$, et al. Identifying patients at high risk for poor outcome after intra-arterial therapy for acute ischemic stroke. Stroke. 2009;40:1780-5.

38. Donnan GA, Baron J-C, Ma H, Davis SM. Penumbral selection of patients for trials of acute stroke therapy. Lancet Neurol. 2009; 8:261-9.

39. Yoo AJ, Verduzco LA, Schaefer PW, et al. MRI-based selection for intra-arterial stroke therapy value of pretreatment diffusionweighted imaging lesion volume in selecting patients with acute stroke who will benefit from early recanalization. Stroke. 2009; 40:2046-54. 